\title{
Ester Hydrogenation Catalyzed by a Ruthenium(II) Complex Bearing an N- Heterocyclic Carbene Tethered with an "NH2" Group and a DFT Study of the Proposed Bifunctional Mechanism
}

\author{
Wylie W. N. O and Robert H. Morris \\ Version Post-print/accepted manuscript \\ Citation Wylie, W. N., \& Morris, R. H. (2012). Ester Hydrogenation Catalyzed \\ (published version) by a Ruthenium (II) Complex Bearing an N-Heterocyclic Carbene \\ Tethered with an "NH2" Group and a DFT Study of the Proposed \\ Bifunctional Mechanism. ACS Catalysis, 3 (1), 32-40. \\ DOI: $10.1021 / \operatorname{cs} 300619 \mathrm{q}$ \\ Publisher's statement This document is the Accepted Manuscript version of a Published \\ Work that appeared in final form in ACS Catalysis, copyright (C) \\ American Chemical Society after peer review and technical editing by \\ the publisher. To access the final edited and published work see \\ http://dx.doi.org/10.1021/cs300619q.
}

How to cite TSpace items

Always cite the published version, so the author(s) will receive recognition through services that track citation counts, e.g. Scopus. If you need to cite the page number of the author manuscript from TSpace because you cannot access the published version, then cite the TSpace version in addition to the published version using the permanent URI (handle) found on the record page.

This article was made openly accessible by $U$ of $T$ Faculty. Please tell us how this access benefits you. Your story matters. 


\section{Table of Contents}

Ester Hydrogenation Catalyzed by a Ruthenium(II) Complex Bearing an N-heterocyclic Carbene Tethered with an "NH2" Group and a DFT Study of a Bifunctional Mechanism

Wylie W. N. O and Robert H. Morris*

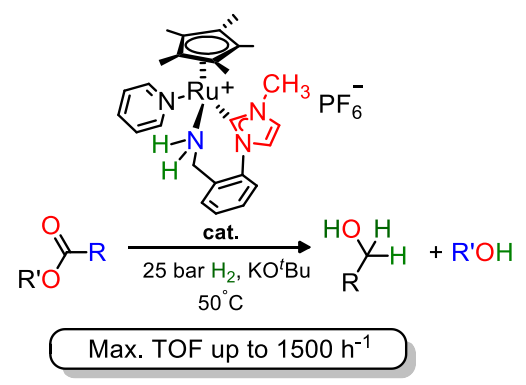

A ruthenium(II) catalyst containing an $\mathrm{NHC}$-amine $\left(\mathrm{C}-\mathrm{NH}_{2}\right)$ ligand catalyzes the $\mathrm{H}_{2}$-hydrogenation of various esters and lactones at mild reaction conditions. In particular a novel steric effect is reported and is explained by DFT calculation of the proposed bifunctional mechanism that involves the "NH" effect. 


\title{
Ester Hydrogenation Catalyzed by a Ruthenium(II) Complex Bearing an N-heterocyclic Carbene Tethered with an " $\mathrm{NH}_{2}$ " Group and a DFT Study of a Bifunctional Mechanism
} Wylie W. N. $O$ and Robert H. Morris*

Davenport Laboratory, Department of Chemistry, University of Toronto, 80 St. George Street, Toronto, Ontario, M5S 3H6, Canada.

*To whom correspondence should be addressed. E-mail: rmorris@chem.utoronto.ca

Keywords: Bifunctional Catalysis, Hydrogenation, Ester, Mechanism, N-Heterocyclic Carbene, Steric Effects, DFT

\begin{abstract}
A ruthenium(II) catalyst containing an $\mathrm{NHC}$-amine $\left(\mathrm{NHC}=\mathrm{N}\right.$-heterocyclic carbene) ligand $\left(\mathrm{C}-\mathrm{NH}_{2}\right)$ catalyzes the $\mathrm{H}_{2}-$ hydrogenation of various esters and lactones at $50^{\circ} \mathrm{C}$ and 25 bar of $\mathrm{H}_{2}$ pressure, mild reaction conditions compared to other reported catalysts. A maximum turnover frequency of $1510 \mathrm{~h}^{-1}$ for the hydrogenation of phthalide with a conversion of $96 \%$ is achieved in $4 \mathrm{~h}$. DFT calculations suggest a concerted, asynchronous bifunctional mechanism for homogeneous ester hydrogenation; a proton transfer step from the $\mathrm{N}-\mathrm{H}$ group of a ruthenium hydride-amine complex to the carbonyl group has the largest energy barrier in the catalytic cycle. The surprising observation is that methyl pivalate $\left({ }^{t} \mathrm{BuCOOCH}_{3}\right)$ is hydrogenated much more rapidly than is tert-butyl acetate $\left(\mathrm{CH}_{3} \mathrm{COO}{ }^{t} \mathrm{Bu}\right)$, it is explained by the energetics of the rate-determining step of the proposed $\mathrm{Ru}-\mathrm{H} / \mathrm{N}-\mathrm{H}$ bifunctional mechanism as calculated.
\end{abstract}

\section{Introduction}

The use of molecular hydrogen in the reduction of polar double bonds is an attractive and green process in organic synthesis. ${ }^{1,2}$ The catalytic hydrogenation of esters with hydrogen using late transition metal catalysts can be beneficial, yet it is still very challenging compared to the reduction of ketones and aldehydes. ${ }^{3-8}$ Thermochemical studies show that the enthalpy of reduction of ethyl acetate by hydrogen to form ethanol is $-17.92 \mathrm{kcal} / \mathrm{mol} .{ }^{9}$ Our calculations $(\mathrm{M} 06 / 6-31++\mathrm{G}(\mathrm{d}$,p)) show that the solventcorrected (tetrahydrofuran, THF) free energy of reaction $(\Delta \mathrm{G})$ in the hydrogenation of methyl acetate to methanol and ethanol is $2.4 \mathrm{kcal} / \mathrm{mol}$. The solvent-corrected enthalpy of reaction $(\Delta \mathrm{H})$ is $-8.2 \mathrm{kcal} / \mathrm{mol}$ (eq. 1 , Scheme 1$){ }^{10}$ This reduction process can be broken into three sequential steps: (a) the hydrogenation of methyl acetate forming 1-methoxyethanol (eq. 2) as the most endogonic step overall $(\Delta \mathrm{G}=9.3 \mathrm{kcal} / \mathrm{mol})$; (b) a $\mathrm{C}-\mathrm{O}$ bond cleavage of the hemiacetal, 1-methoxyethanol, forming acetaldehyde and methanol, as driven by entropy (eq. 3), (c) the reduction of acetaldehyde to ethanol by hydrogen, which is both exergonic and exothermic, as expected (eq. 4). ${ }^{10,11}$

\section{Scheme 1. Thermodynamics of the Hydrogenation of Methyl Acetate to Methanol and Ethanol} G (kcal $/ \mathrm{mol}, \quad H$ (kcal $/ \mathrm{mol}$,

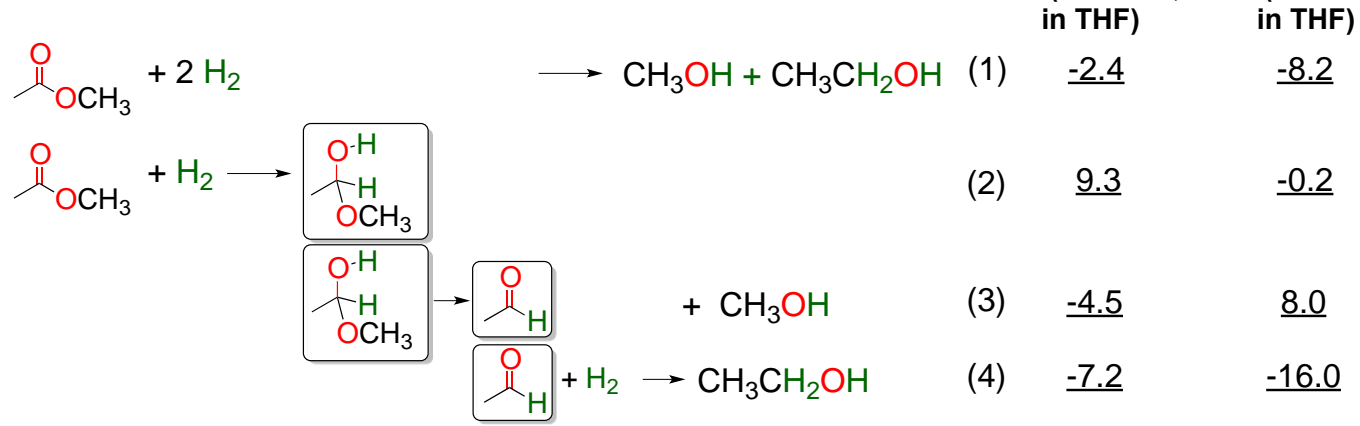

In the area of bifunctional catalysis, ${ }^{12,13}$ seminal work reported by Milstein and co-workers uses catalyst 1a for the hydrogenation of methyl benzoate $\left(5.3 \mathrm{~atm}, 115^{\circ} \mathrm{C}\right)$ to achieve a complete conversion to benzyl alcohol and methanol in $4 \mathrm{~h}$, with a turnover number (TON) of 100 (Chart 1$).^{5}$ Catalysts $\mathbf{1} \mathbf{b}^{14}$ and $\mathbf{1} \mathbf{c}^{15}$ that are structurally similar to $\mathbf{1 a}$ also gave good activities in ester hydrogenation. Notably, complex $\mathbf{1 c}$ is the first catalyst containing a functionalized N-heterocyclic carbene ${ }^{16}$ for the efficient hydrogenation of esters at low $\mathrm{H}_{2}$ pressure $\left(5.3 \mathrm{bar}, 105^{\circ} \mathrm{C}\right) .{ }^{15}$ 
Chart 1. Ruthenium(II)-based Bifunctional Catalysts for the Hydrogenation of Esters: (a) Milstein-type Complexes 1a to $1 \mathrm{c}$, and (b) Complexes 1d to 2 Containing an "NH" Functionality

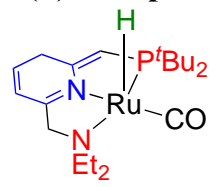

$1 \mathrm{a}$

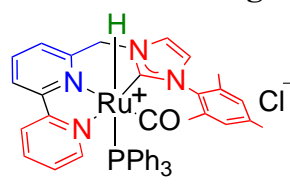

$1 b$

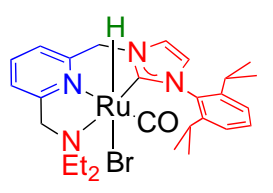

1c

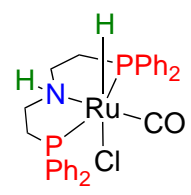

1d

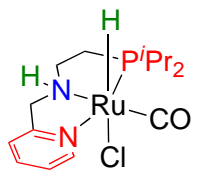

1e-Ru

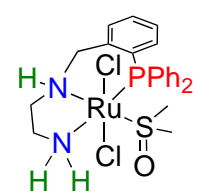

$1 f$

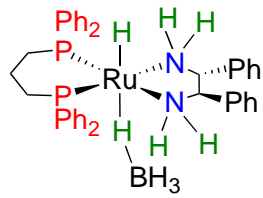

$1 \mathrm{~g}$

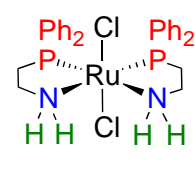

$1 \mathrm{~h}$

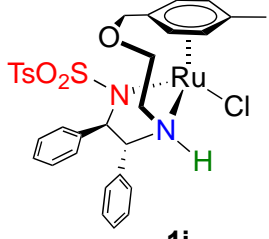

$1 \mathbf{i}$

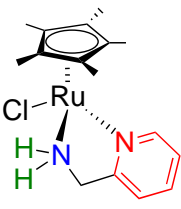

$1 \mathrm{j}$

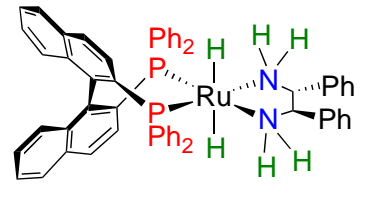

$1 \mathrm{k}$

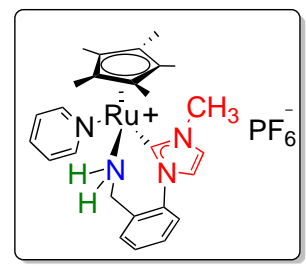

(2)

Bifunctional catalysts 1d and $\mathbf{1 h}$, containing a phosphine-amine (P-NHR) linkage, have been reported by the Firmenich and the Takasago groups as efficient catalysts for the hydrogenation of esters. ${ }^{6,17,18}$ Gusev and co-workers used complex $\mathbf{1 e - R u}$ bearing a pincer-type $\mathrm{P}-\mathrm{NH}-\mathrm{N}$ ligand in the hydrogenation of alkenoates. ${ }^{19}$ Its osmium(II) analogue, 1e-Os, was used in the hydrogenation of saturated triglycerides giving cetyl and stearyl alcohols (Chart 1). ${ }^{20}$ Clarke and co-workers has recently reported a similar complex 1 f containing a pincer-type $\mathrm{P}-\mathrm{NH}-\mathrm{NH}_{2}$ ligand for ester hydrogenation. ${ }^{21}$ The borohydride complex $\mathbf{1 g}$ also showed excellent activity in ester hydrogenation. ${ }^{18}$ Ikariya and co-workers showed that the piano-stool complexes $\mathbf{1} \mathbf{i},{ }^{22}$ and $\mathbf{1} \mathbf{j}^{23}$ with a bidentate pyridyl-amine ligand catalyze the hydrogenation of lactones and cyclic carboxamides. The phosphine-amine analogue, however, has poor activity in ester hydrogenation. ${ }^{23}$ Of note, most of these catalysts use relatively high hydrogen pressure (up to 50 atm) and elevated temperatures (up to $100^{\circ} \mathrm{C}$ ) to achieve conversion of the ester to the corresponding alcohols, though the hydrogenation of fluorinated esters using catalyst $\mathbf{1 d}$ can be achieved at 9 atm of hydrogen and up to $40^{\circ} \mathrm{C}^{8}$ It is believed an "NH" mechanism ${ }^{12,13,24,25}$ might be responsible for the high activity in ester hydrogenation that was observed. ${ }^{6,19,23}$

The mechanisms of ester hydrogenation allowed by these catalysts have received little experimental investigation. Bergens and coworkers have observed the first intermediate by NMR spectroscopy from the reaction of the "NH" containing catalyst $\mathbf{1 k}$ and $\gamma$ butyrolactone (Chart 1). ${ }^{26}$ There are also a few computational studies on the dehydrogenative coupling of alcohols and amides using the Milstein catalyst $1 \mathbf{a},{ }^{27,28}$ a reaction which is closely related to the hydrogenation of amides. More recently, computationally studies ${ }^{29,30}$ on the mechanism of the hydrogenation of dimethyl carbonate to methanol using catalyst $1 \mathbf{a}^{31}$ have been reported.

We previously showed that complex 2 that contains an N-heterocyclic carbene with a tethered primary-amine donor $\left(\mathrm{C}-\mathrm{NH}_{2}\right)$ is an active catalyst for the hydrogenation of a variety of ketones using molecular hydrogen under very mild reaction conditions $(8$ bar, $25^{\circ} \mathrm{C}$, Chart 1). ${ }^{32}$ Our studies showed that an alcohol-assisted outer-sphere bifunctional mechanism accounted for the activity that was observed in ketone hydrogenation. ${ }^{11}$ Herein, we report our results for ester hydrogenation using complex 2 . This uses a moderate hydrogen pressure $(25 \mathrm{bar})$ and the reactions are carried out at a lower temperature $\left(50^{\circ} \mathrm{C}\right)$ than for other reported catalysts in ester hydrogenation reactions. We also report the first computational study of an outer-sphere bifunctional mechanism for ester hydrogenation that utilizes the "NH" effect.

\section{Results and Discussion}

Ester hydrogenation catalyzed by ruthenium complex 2 . The reduction of methyl benzoate was studied first. ${ }^{32}$ Complex 2 catalyzed the hydrogenation of methyl benzoate in THF to benzyl alcohol and methanol to $78 \%$ conversion in $2 \mathrm{~h}$ under 25 bar of $\mathrm{H}_{2}$ pressure at $50^{\circ} \mathrm{C}$ and in the presence of 8 equiv. with respect to catalyst $(\mathrm{C})$ of potassium tert-butoxide (KO$\left.{ }^{t} \mathrm{Bu}\right)$ as the base (B). This corresponds to a turnover frequency of $838 \mathrm{~h}^{-1}$ (catalyst to substrate ratio $(\mathrm{C} / \mathrm{S})=1 / 1500$ ). Catalysis proceeds at a slower rate at lower temperature and $\mathrm{H}_{2}$ pressure (Table 1, entries 1-2). The aforementioned reaction conditions were used to extend our investigations to other esters and lactones in the present work. Of note, esters that are formed from the transesterification of the product alcohols were not observed. ${ }^{6}$ 
Table 1. Hydrogenation of Esters Catalyzed by Complex $2^{a}$

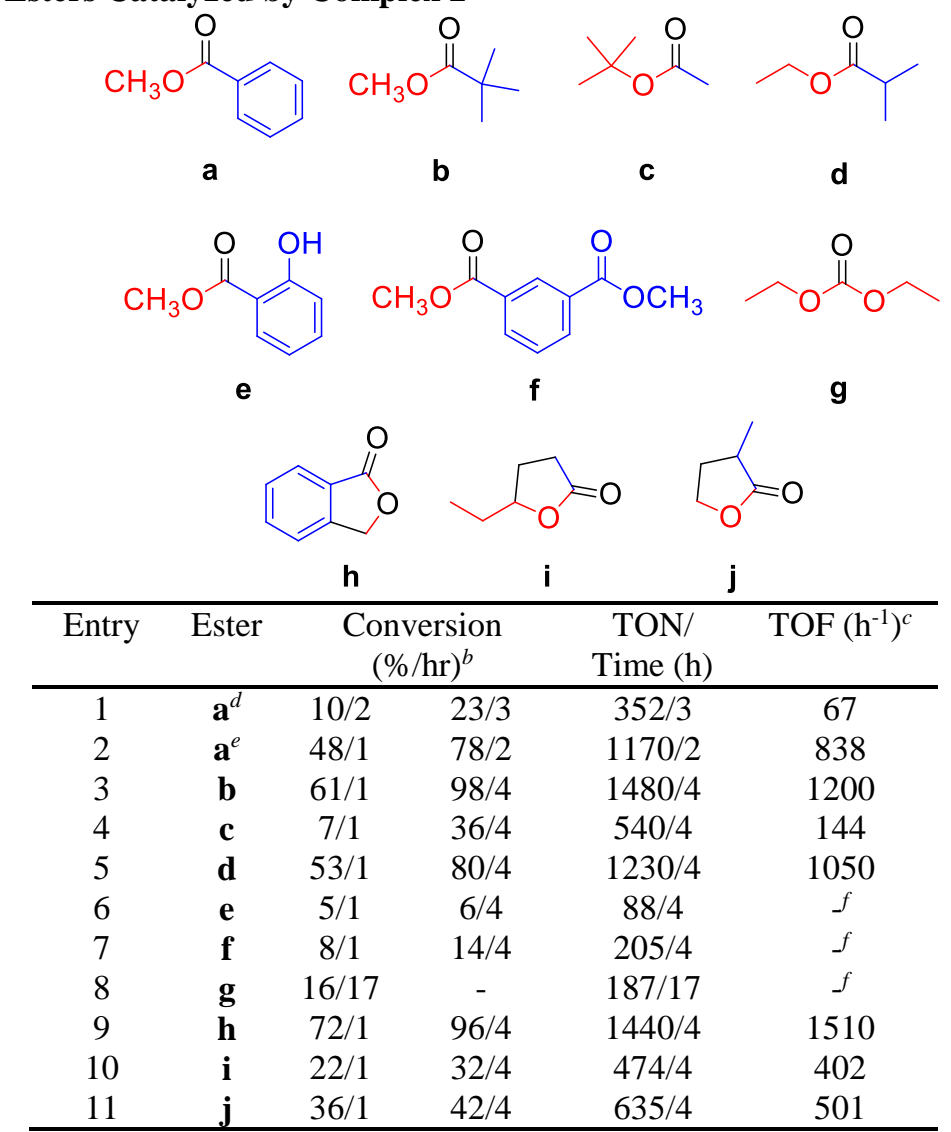

${ }^{a}$ Reactions were carried out in a $50 \mathrm{~mL}$ Parr hydrogenation reactor at 25 bar of $\mathrm{H}_{2}$ pressure at $50^{\circ} \mathrm{C}$ using $\mathrm{THF}(6 \mathrm{~mL})$ as the solvent, $2(7.7 \mu \mathrm{mol})$ as the catalyst, $\mathrm{KO}^{t} \mathrm{Bu}(59 \mu \mathrm{mol})$ as the base, and the corresponding ester $(1.16 \mathrm{M})$ as the substrate. The $\mathrm{C} / \mathrm{B} / \mathrm{S}$ ratio was $1 / 8 / 1500 .{ }^{b}$ Conversions of the esters were determined with $n$-tridecane as an internal standard for GC analysis, and were reported as an average of at least two runs. The identities of the alcohol products were determined by ${ }^{1} \mathrm{H}$ and ${ }^{13} \mathrm{C}$ NMR in $\mathrm{CDCl}_{3}$. ${ }^{c}$ Determined from the slope of the linear portion in the reaction profile. ${ }^{d}$ Reaction was carried out at $25^{\circ} \mathrm{C}$. See ref. 32 . ${ }^{e}$ Reaction was carried out at $50^{\circ} \mathrm{C}$. See ref. 32. ${ }^{f}$ TOF not measured.

Aliphatic esters such as methyl pivalate (b) and ethyl isobutyrate (d) were hydrogenated efficiently to their corresponding alcohols in $98 \%$ and $80 \%$ conversions in $4 \mathrm{~h}$, respectively. TOF values of 1200 and $1050 \mathrm{~h}^{-1}$ were achieved for these substrates. These esters have bulky groups attached adjacent to the carbonyl functionality. On the other hand, tert-butyl acetate (c) was hydrogenated much more slowly than $\mathbf{b}$ and $\mathbf{d}$, giving a conversion of $36 \%$ and a TOF value of $144 \mathrm{~h}^{-1}$. This has a bulky group attached to the ester oxygen (entries 3-5). These observations were studied further by computational studies (see below).

The hydrogenation of methyl benzoates substituted at the phenyl group, on the other hand, is challenging. The hydrogenation of methyl salicylate (e) and dimethyl isophthalate (f) gave poor TON values (88 and 205, respectively) in 4 h. The latter gave an approximate 1 to 1 ratio of a mixture of 1,3-benzenedimethanol and 1-methyl-3-(hydroxymethyl)benzoate as the products (entries 6 and 7).

The hydrogenation of diethyl carbonate $(\mathbf{g})$ was tested as well. This gave methanol and ethanol as the major products in $17 \mathrm{~h}$ with a TON value of 187 (entry 8). This has a lower activity than that of complex 1a (TON = 910 in $8 \mathrm{~h}$ based on ethanol), ${ }^{31}$ and a much lower one than the hydrogenation of dimethyl carbonate catalyzed by the hydrido-amido complex of $\mathbf{1 e - R \mathbf { u }}(\mathrm{TON}=1700$ in 5.7 h) ${ }^{19}$ on the other hand, these two systems utilize higher temperatures and hydrogen pressures. ${ }^{19,31}$

A series of lactones were tested for hydrogenation reactions using complex $\mathbf{2}$ as the catalyst. Phthalide (h) was hydrogenated to 1,2-benzenedimethanol in $96 \%$ conversion in $4 \mathrm{~h}$ with a TOF value of $1510 \mathrm{~h}^{-1}$. This represents much greater catalytic activity than for complex $\mathbf{1 j}\left(\mathrm{TON}=89\right.$ in $5 \mathrm{~h}$, at $50 \mathrm{~atm}$ and $\left.100^{\circ} \mathrm{C}\right){ }^{23}$ The aliphatic lactones $\mathbf{i}$ and $\mathbf{j}$ were hydrogenated to their corresponding diols as the only products, confirmed by ${ }^{1} \mathrm{H}$ and ${ }^{13} \mathrm{C}$ NMR spectroscopy, with TOF values of 402 and $501 \mathrm{~h}^{-1}$, respectively (entries 9-11). Of interest, the lactone $\mathbf{j}$, which contains a methyl group at the $\alpha$-carbon position adjacent to the ester functionality, was hydrogenated faster than $\mathbf{i}$, which lacks such a methyl group. 
The reaction profile for ester hydrogenation was sigmoidal with variable induction periods depending on the substrate of interest (Figure 1). This observation was similar to ketone hydrogenation catalyzed by complex $2^{11,32}$ and some other ketone hydrogenation catalysts. Such an observation was attributed to an alcohol-assisted mechanism where the alcohol product acts a proton shuttle to aid in the heterolytic splitting of the $\eta^{2}-\mathrm{H}_{2}$ ligand. ${ }^{11,32,33}$ In the case of the hydrogenation of aliphatic lactones $(\gamma$-caprolactone (i), for example, Figure 1), the reaction profile plot plateaus at around 30\% conversion at which point the TOF decreases.

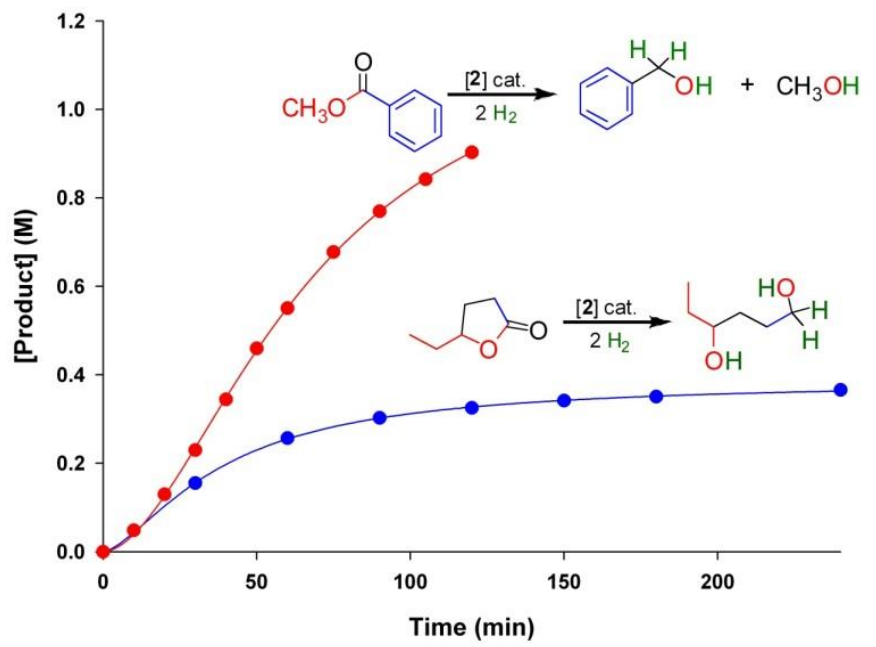

Figure 1. Reaction profiles showing the hydrogenation of methyl benzoate (a, in red) and $\gamma$-caprolactone (i, in blue) catalyzed by complex 2 in THF at 25 bar of $\mathrm{H}_{2}$ pressure and $50^{\circ} \mathrm{C}$ in the presence of $\mathrm{KO}{ }^{\mathrm{t}} \mathrm{Bu}$ as the base. The $\mathrm{C} / \mathrm{B} / \mathrm{S}$ ratio was $1 / 8 / 1500$.

Computational studies of an outer-sphere bifunctional mechanism for ester hydrogenation. We propose, based on the results of our calculations by DFT methods, an outer-sphere bifunctional mechanism for ester hydrogenation catalyzed by complex 2 . The M06 $^{34,35}$ functional was used as this was shown to give better predictions of geometric parameters in organometallic compounds. ${ }^{35}$, ${ }^{36}$ Solvent correction (THF) was made to the gas-phase-optimized structures using the intergral equation formalism polarization continnum model (IEF-PCM) ${ }^{37,38}$ with radii and nonelectrostatic terms from Truhlar's SMD solvation model. ${ }^{39}$ A reaction of the precatalyst 2 with $\mathrm{KO}^{t} \mathrm{Bu}$ is assumed to afford a ruthenium(II) amido complex in the catalyst activation step. ${ }^{11}$ The catalytic cycle (Scheme 2) then follows, which consists of four important steps: (1) the activation of $\mathrm{H}_{2}$ by the ruthenium amido complex (step $\mathrm{A}) ; 1,11,25$ (2) the transfer of the bifunctional $\mathrm{Ru}-\mathrm{H} / \mathrm{N}-\mathrm{H}$ pair from the ruthenium hydride-amine complex to an ester in the outersphere, via a 6-membered ring transition state, forming a hemiacetal molecule (step B); (3) ruthenium-assisted cleavage of the $\mathrm{C}-\mathrm{O}$ bond of the hemiacetal coupled with proton transfer from the hydroxyl oxygen to the amido nitrogen via a 6-membered ring transition state $($ step $\mathrm{C}) ;^{28}(4)$ regeneration of the ruthenium hydride-amine complex, and the reduction of the aldehyde in the outersphere via a similar transition state (step D), this is given in full details in the SI. The $\eta^{5}$-pentamethylcyclopentadienyl ligand was simplified to an $\eta^{5}$-cyclopentadienyl (Cp) ligand to ease computation. Methyl acetate was used as the model substrate unless otherwise stated. 


\section{Scheme 2. Proposed Mechanism for the Outer-sphere Bifunctional Mechanism for Ester Hydrogenation}

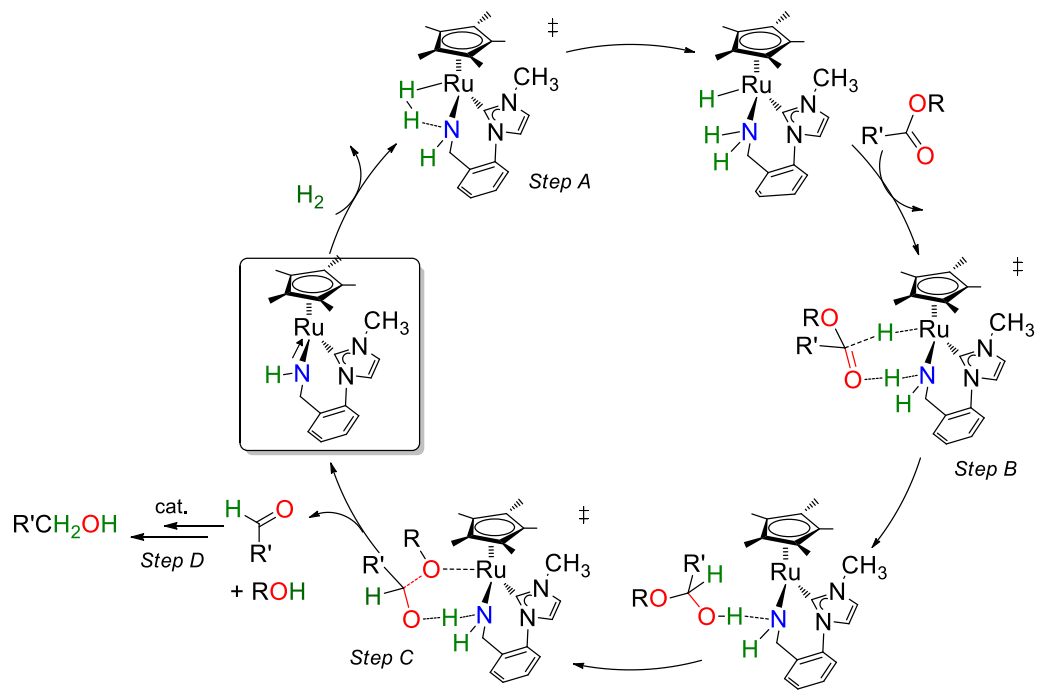

Activation of $\mathbf{H}_{2}$ (Step A). At the initial stage of reaction (Step A in Scheme 2), the amido complex A activates a hydrogen molecule via coordination to ruthenium $\left(\mathbf{T S}_{\mathbf{A}, \mathbf{B}}\right)$, forming $\mathbf{B}$ containing an $\eta^{2}-\mathrm{H}_{2}$ ligand. Subsequent heterolytic splitting of the $\eta^{2}$ $\mathrm{H}_{2}$ ligand across the ruthenium-amido bond (TS $\mathbf{B}, \mathbf{C}$ ) leads to the hydride-amine complex $\mathbf{C}$ (Scheme 3). The solvent-corrected free energy barriers $\left(\Delta \mathrm{G}_{\mathrm{THF}}^{\ddagger}\right)$ for the coordination and heterolytic splitting of hydrogen are $16.1 \mathrm{kcal} / \mathrm{mol}\left(\Delta \mathrm{H}^{\ddagger} \mathrm{THF}=7.6 \mathrm{kcal} / \mathrm{mol}\right)$ and $18.0 \mathrm{kcal} / \mathrm{mol}\left(\Delta \mathrm{H}_{\mathrm{THF}}^{\ddagger}=9.6 \mathrm{kcal} / \mathrm{mol}\right)$, respectively, starting from the model amido complex $\mathbf{A}$ and hydrogen. The gas phase free energy barriers for the coordination and the heterolytic splitting of hydrogen are similar (15.8 and $16.3 \mathrm{kcal} / \mathrm{mol}$, respectively). These are similar results compared to our previous calculations using the MPW1PW91 functional. ${ }^{11}$ Of interest, the hydride-amine complex $\mathbf{C}$ is $-4.7 \mathrm{kcal} / \mathrm{mol}$ more stable $\left(\Delta \mathrm{G}_{\mathrm{THF}}=-7.9 \mathrm{kcal} / \mathrm{mol}\right)$ than the amido complex $\mathbf{A}$ and hydrogen $(\Delta \mathrm{G}(\mathrm{MPW} 1 \mathrm{PW} 91)=-$ $8.8 \mathrm{kcal} / \mathrm{mol})$.

Scheme 3. Activation of $\mathrm{H}_{2}$ Starting from the Amido Complex A (Step A in Scheme 2). ${ }^{a}$

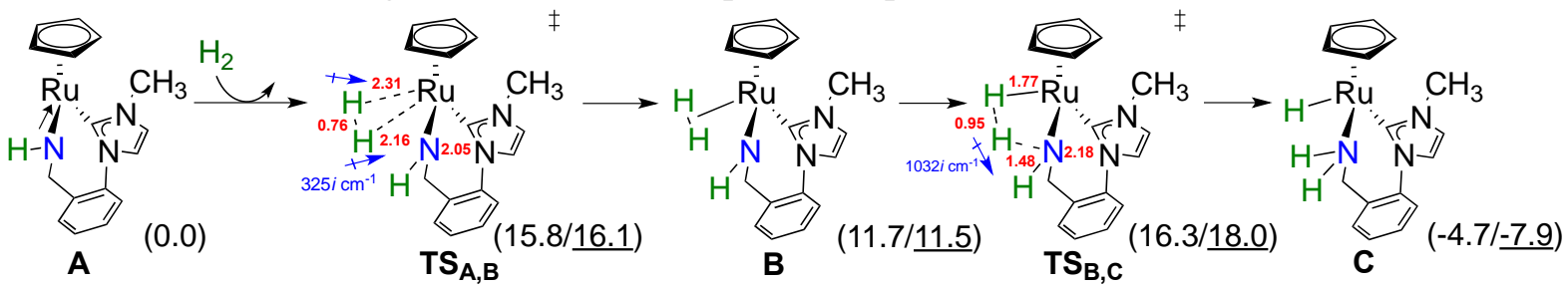

${ }^{a}$ The gas phase and the solvent-corrected free energies (M06/1 atm, and THF, $298 \mathrm{~K}$ ) are given in parentheses (in kcal/mol) relative to $\mathbf{A}$ and $\mathrm{H}_{2}$. The calculated bond lengths (in $\AA$ ) and the imaginary vibrational frequencies (in $\mathrm{cm}^{-1}$ ) are given in the structures $\mathbf{T S}_{\mathbf{A}, \mathbf{B}}$ and $\mathbf{T S}_{\mathbf{B}, \mathrm{C} \text {. }}$

Bifunctional addition of a hydride/proton pair across the carbonyl group of methyl acetate (Step B). The hydride-amine complex $\mathbf{C}$ that forms from the heterolytic splitting of $\mathrm{H}_{2}$ at the amido complex $\mathbf{A}$ transfers its bifunctional $\mathrm{Ru}-\mathrm{H} / \mathrm{N}-\mathrm{H}$ pair to methyl acetate in the outer-coordination sphere via a 6-membered ring transition state, involving hydrogen bonding of the $\mathrm{N}-\mathrm{H}$ group with the oxygen of the ester, and an attack of the carbonyl carbon by the $\mathrm{Ru}-\mathrm{H}$ group (Step B in Scheme 2). A transition state search reveals only one structure $\mathbf{T S}_{\mathbf{D}, \mathbf{E}}$. The solvent-corrected free energy barrier on going from $\mathbf{C}$ and methyl acetate to such a transition state is $22.3 \mathrm{kcal} / \mathrm{mol}$. The final product $\mathbf{E}$, which consists of the amido complex $\mathbf{A}$ and a $(S)-1$-methoxyethanol molecule hydrogen-bonded through its hydroxyl oxygen to the amido nitrogen, is $0.9 \mathrm{kcal} / \mathrm{mol}$ lower than $\mathbf{T} \mathbf{S}_{\mathbf{D}, \mathbf{E}}$ (Scheme 4). This results from a $R e$-face attack by the $\mathrm{Ru}-\mathrm{H}$ bond to the carbonyl group of the ester. The solvent-corrected free energy barrier to reach to a similar transition state $\left(\mathbf{T S}_{\mathbf{D}, \mathbf{E}}\right.$ ') as a result of a $\mathrm{Si}$-face attack by the $\mathrm{Ru}-\mathrm{H}$ bond is $22.2 \mathrm{kcal} / \mathrm{mol}$. 
Scheme 4. Bifunctional Addition of a Hydride/proton Pair across the Carbonyl Group of Methyl Acetate Starting from the Hydride Complex C (Step B in Scheme 2). ${ }^{a}$

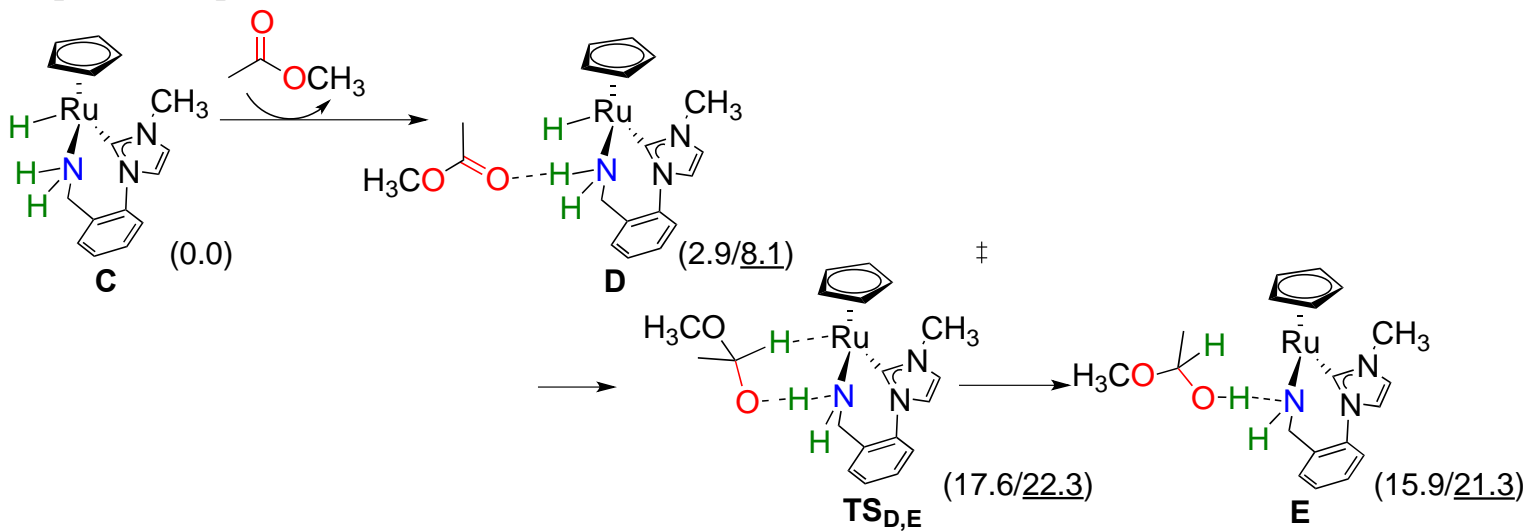

${ }^{a}$ The gas phase and solvent-corrected free energies (M06/1 atm, and THF, $298 \mathrm{~K}$ ) are given in parentheses (in kcal/mol) relative to $\mathbf{C}$ and methyl acetate.

The structure $\mathbf{T S}_{\mathbf{D}, \mathbf{E}}$ is a late transition state involving a proton transfer step ${ }^{40-42}\left(v=1040 i \mathrm{~cm}^{-1}\right)$ from the amine nitrogen to the carbonyl oxygen of methyl acetate $(\mathrm{N}-\mathrm{H} 2=1.19 ; \mathrm{Ru}-\mathrm{H} 1=1.93 \AA$, Figure 2, top). The structure TS $\mathbf{D}, \mathbf{E}$ ' also has similar geometric parameters $\left(\mathrm{v}=939 i \mathrm{~cm}^{-1}\right.$, see the SI, Figure S1). An intrinsic reaction coordinate (IRC) calculation on the forward reaction from D to $\mathbf{T S}_{\mathbf{D}, \mathbf{E}}$ shows an absence of a local maximum in the reaction profile. This suggests that a transition state structure of a hydride transfer step is likely to be situated on a flat potential energy surface (PES, see Figures S5 and S6 in SI). ${ }^{43-45}$ In addition, the presence of a saddle point in the reaction profile shows that an ion-pair structure containing an agostic interaction of the $\mathrm{C}-\mathrm{H}$ bond (C- H1 1.32; Ru-H 1.86 $\AA$ ) of 1-methoxyethoxide with the ruthenium center ${ }^{10,11,41,42}$ is likely to be present as a short-lived intermediate during the course of the reaction. All of these are indicative of a concerted, asynchronous bifunctional mechanism ${ }^{41}$ in ester hydrogenation as observed in ketone hydrogenation. ${ }^{24,41,46}$

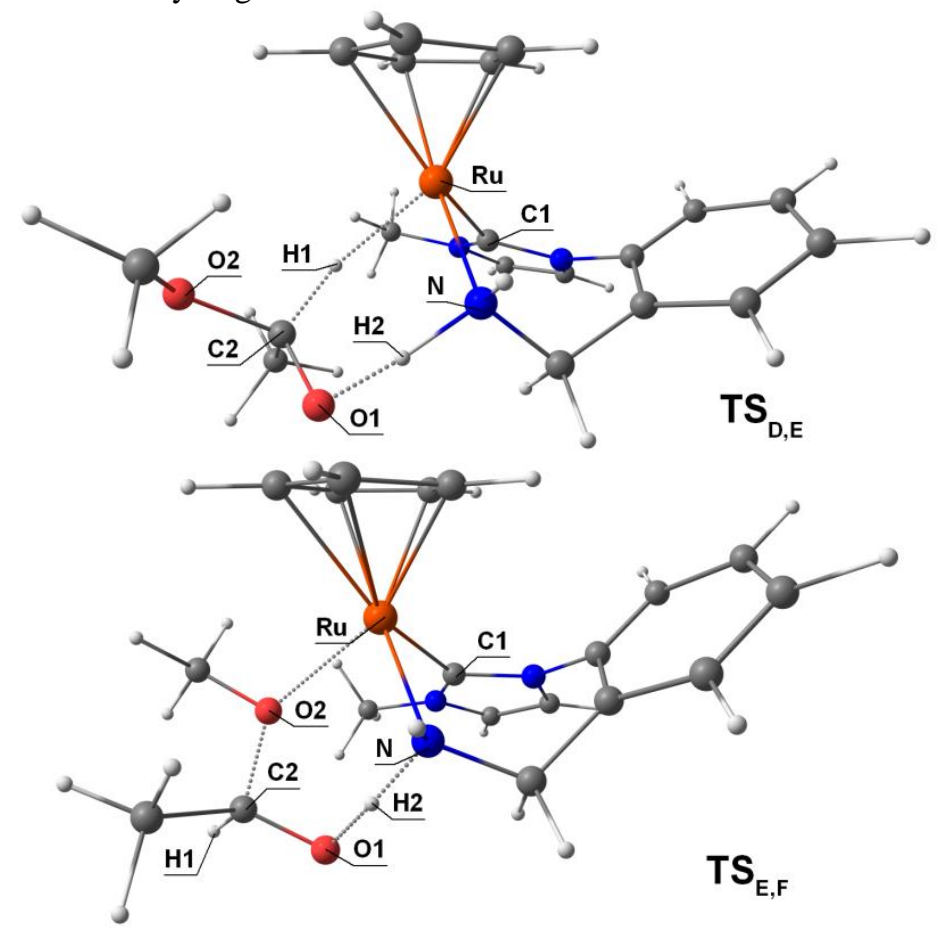

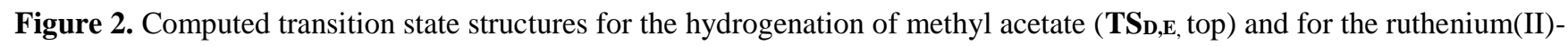

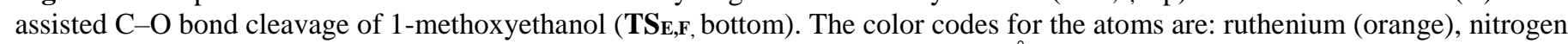

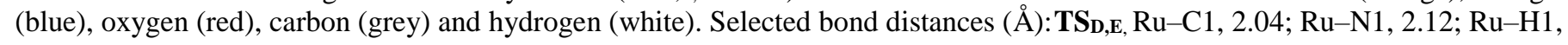
1.93; C2-H1, 1.21; N-H2 1.19; O1-H2, 1.29; C2-O1, 1.31; C2-O2, 1.42; TSE,F, Ru-C1, 2.05; Ru-N1, 2.17; Ru-O2, 2.31; N-H2, $1.20 ; \mathrm{O} 1-\mathrm{H} 2,1.29 ; \mathrm{C} 2-\mathrm{O} 1,1.32 ; \mathrm{C} 2-\mathrm{O} 2,1.52$. 
Explanation of a Steric effect in Ester Hydrogenation. We have also computed similar transition states for such a proton transfer step starting from methyl pivalate and tert-butyl acetate as the substrates. These results are summarized in Figure 3 and Table 2. The steric effect for non-transition metal catalyzed ketone hydrogenation has been studied computationally. ${ }^{47}$ When a bulky tertbutyl group was attached adjacent to the carbonyl functionality (b), the solvent-corrected energy barriers $\left(\Delta \mathrm{G}^{\star} \mathrm{THF}, \Delta \mathrm{H}^{\star} \mathrm{THF}\right.$ and $\Delta \mathrm{E}_{\mathrm{THF}}^{\ddagger}$ ) are smaller relative to those of methyl acetate (entries 1, 2, 5 and 6). On the other hand, the barriers are larger starting from ester $\mathbf{c}$, in which a tert-butyl group is now attached to the ester oxygen (entries 3-6). These observations explain our experimental findings as described above. Of interest, the free energy barriers as a result of a $\mathrm{Si}$-face attack on the carbonyl group by the metal hydride via $\mathbf{T S}_{\mathbf{D}, \mathbf{E}^{\prime}}$ are about $1 \mathrm{kcal} / \mathrm{mol}$ smaller for esters $\mathbf{b}$ and $\mathbf{c}$. These have OR group $(\mathrm{R}=$ methyl, tert-butyl) pointing away from the metal center and the $\mathrm{N}-\mathrm{H}$ functionality.

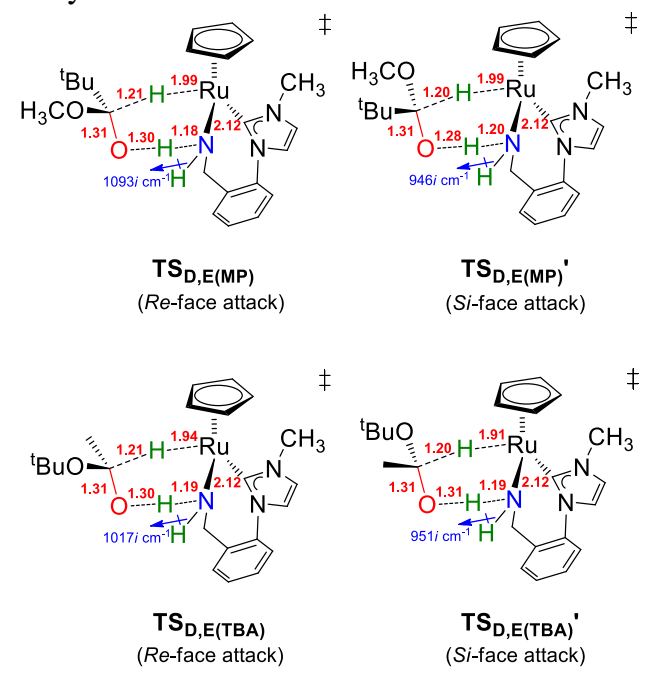

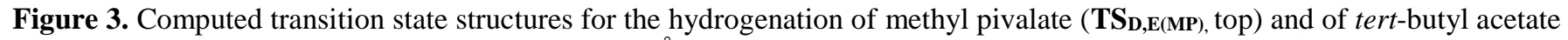

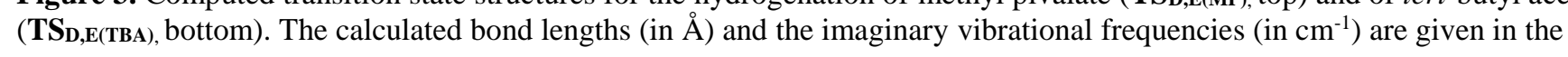
structures.

A direct comparison of the solvent-corrected ground state free energies $\left(\Delta \mathrm{G}_{T H F}\right)$ of the substrates $\left(\mathrm{C}_{6} \mathrm{H}_{12} \mathrm{O}_{2}\right)$ b (methyl pivalate) and $\mathbf{c}$ (tert-butyl acetate) reveals that $\mathbf{c}$ is $6.7 \mathrm{kcal} / \mathrm{mol}$ more stable than $\mathbf{b}$. In fact, the ground state free energy of ethyl isobutyrate (d from Table 1) was calculated to be $2.9 \mathrm{kcal} / \mathrm{mol}$ more stable than $\mathbf{b}$. It appears the relative stability of the ester substrates has a significant impact in contributing to the difference in barrier heights that was computed, thus the difference in rates of hydrogenation that was observed experimentally. In fact, the transition state energies (G, H and E) of TSS,E(MP) and TS $\mathbf{T}, \mathbf{E}$ (TBA) (or

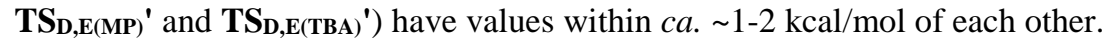

Table 2. Computed Solvent-corrected Energy Barriers for the Proton Transfer Step Involving a Bifunctional Ru-H/N-H pair of Complex $\mathrm{C}$ and Esters of Interest

\begin{tabular}{|c|c|c|c|c|c|}
\hline & & b & c & $\mathbf{h}$ & \\
\hline Entry & Ester & $\begin{array}{c}\text { Transition } \\
\text { States }\end{array}$ & $\begin{array}{c}\Delta \mathrm{G}^{\ddagger} \mathrm{THF} \\
(\mathrm{kcal} / \mathrm{mol})^{a}\end{array}$ & $\begin{array}{c}\Delta \mathrm{H}^{\ddagger} \mathrm{THF} \\
(\mathrm{kcal} / \mathrm{mol})^{b}\end{array}$ & $\begin{array}{c}\Delta \mathrm{E}^{\ddagger} \mathrm{THF} \\
(\mathrm{kcal} / \mathrm{mol})^{c}\end{array}$ \\
\hline 1 & b & TS & 21.3 & 11.4 & 13.7 \\
\hline 2 & b & $\mathbf{T S}_{\mathbf{D}, \mathbf{E}(\mathbf{M P})^{\prime}}$ & 19.7 & 10.1 & 13.0 \\
\hline 3 & c & $\mathbf{T S}_{\mathbf{D}, \mathbf{E}(\mathbf{T B A})}$ & 26.6 & 15.1 & 17.5 \\
\hline 4 & c & $\mathbf{T S}_{\mathbf{D}, \mathbf{E}(\mathrm{TBA})}$ & 25.5 & 14.2 & 17.0 \\
\hline 5 & h & $\mathbf{T S} \mathbf{S}_{\mathbf{D}, \mathbf{E}}$ & 22.3 & 11.5 & 13.9 \\
\hline 6 & $\mathbf{h}$ & $\mathbf{T S}_{\mathbf{D}, \mathbf{E}^{\prime}}$ & 22.2 & 11.0 & 13.1 \\
\hline
\end{tabular}

${ }^{a}$ Measured relative to $\mathbf{C}$ and the corresponding ester. ${ }^{b}$ Measured relative to $\mathbf{D} .{ }^{c}$ Electronic energy. Measured relative to $\mathbf{D}$.

Effect of Conformational Differences in Ester Hydrogenation. We also investigated the effect of the alkoxy group of the ester that is either syn- or anti-coplanar to the carbonyl functionality to the energy barrier for bifunctional addition of an $\mathrm{H}^{+} / \mathrm{H}^{-}$pair across a carbonyl group of the ester, as a result of free rotation about the $\mathrm{C}-\mathrm{O}$ bond. We have considered a syn-coplanar conformation of the alkoxy group of all of the esters throughout (vide supra). The discussion of the anti-coplanar conformation 
will be given here. The solvent-corrected free energy barrier for the hydrogenation of methyl acetate (h) via a Re-face attack by the

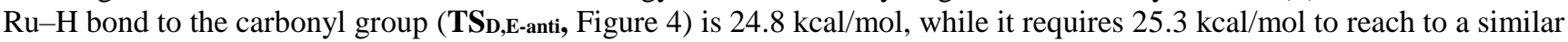

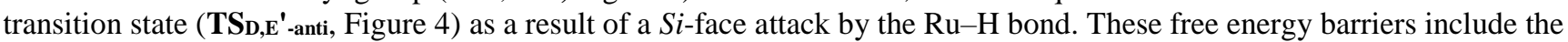
difference in ground state energies of syn- and anti-conformers of methyl acetate, for which the latter is $4.2 \mathrm{kcal} / \mathrm{mol} \mathrm{higher}$ than its syn-configuration. On the other hand, the geometric parameters of all of these transition states are strikingly similar (Figure 4). Of

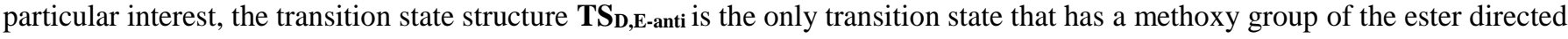
towards the coordinated $\eta^{5}$-Cp ligand (Figure 5). It is expected that the barrier height for an analogous transition state for tert-butyl acetate (c) will be much higher because of the steric interaction of the tert-butyl group with the coordinated $\eta^{5}$-Cp ligand.

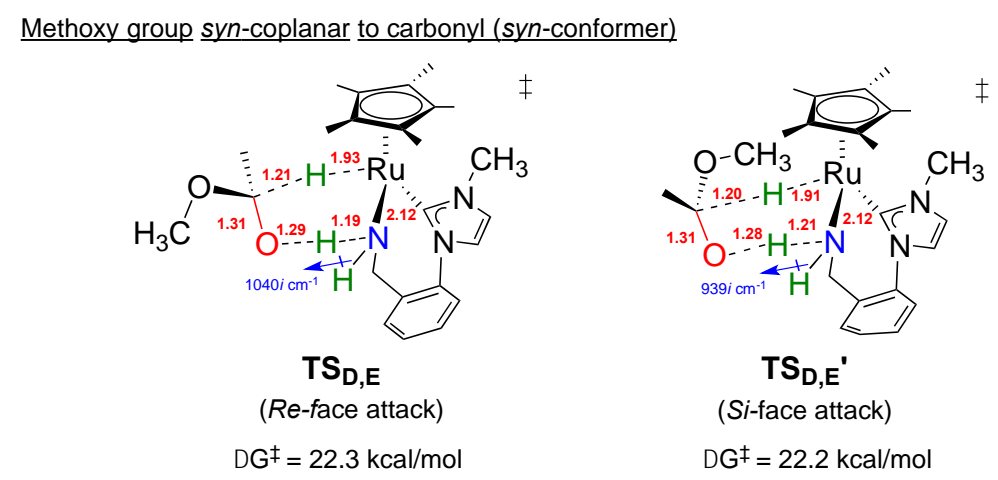

Methoxy group anti-coplanar to carbonyl (anti-conformer)
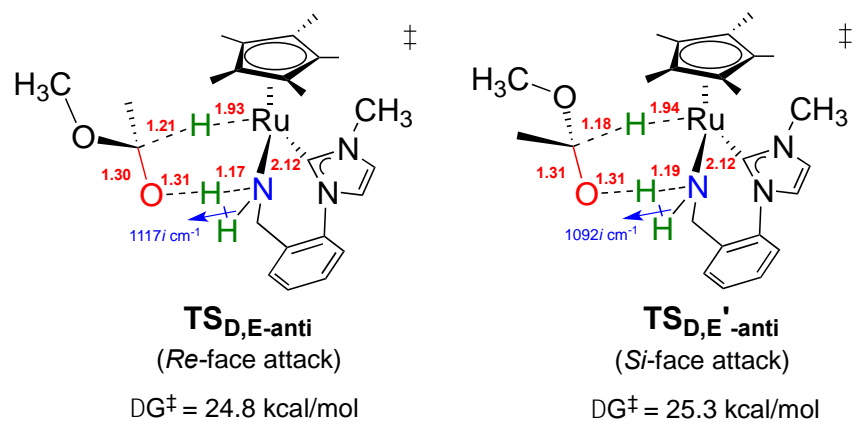

Figure 4. Computed transition state structures for the hydrogenation of methyl acetate $\left(\mathbf{T S}_{\mathbf{D}, \mathbf{E}}\right)$ with methoxy group of the ester syn-coplanar (above) or anti-coplanar (below) to the carbonyl group. The calculated bond lengths (in $\AA$ ) and the imaginary vibrational frequencies $\left(\right.$ in $\mathrm{cm}^{-1}$ ) are given in the structures.

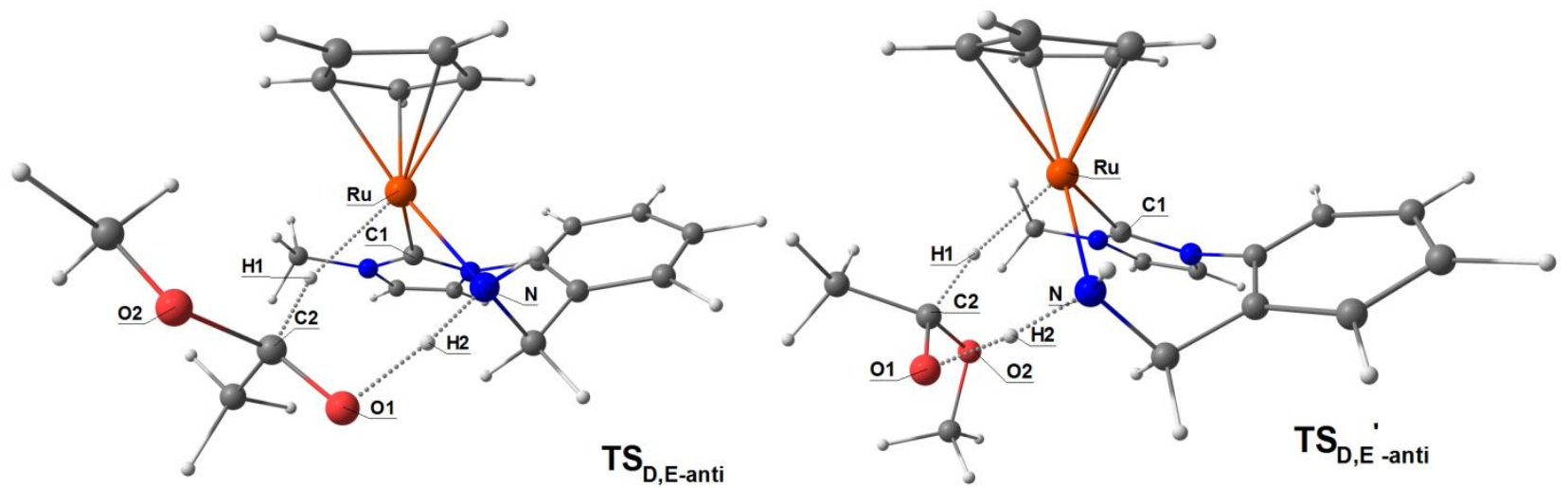

Figure 5. Computed transition state structures for the hydrogenation of methyl acetate via a $R e$-face (TSD,E-anti) or a $S i$-face attack (TS ${ }_{\text {D,E }}{ }^{\prime}$-anti) by the ruthenium hydride. The methoxy group of the ester is anti-coplanar to the carbonyl functionality. The color codes for the atoms are: ruthenium (orange), nitrogen (blue), oxygen (red), carbon (grey) and hydrogen (white). Selected bond distances ( $\AA$ ): TS $S_{\text {D,E-anti, }} \mathrm{Ru}-\mathrm{C} 1,2.04 ; \mathrm{Ru}-\mathrm{N} 1,2.12 ; \mathrm{Ru}-\mathrm{H} 1,1.93 ; \mathrm{C} 2-\mathrm{H} 1,1.21 ; \mathrm{N}-\mathrm{H} 2,1.17 ; \mathrm{O} 1-\mathrm{H} 2,1.31 ; \mathrm{C} 2-\mathrm{O} 1,1.30 ; \mathrm{C} 2-\mathrm{O} 2$, 1.43; TS D,E 'Enti $_{\text {' }} \mathrm{Ru}-\mathrm{C} 1,2.04 ; \mathrm{Ru}-\mathrm{N} 1,2.12 ; \mathrm{Ru}-\mathrm{H} 1,1.94 ; \mathrm{C} 2-\mathrm{H} 1,1.18 ; \mathrm{N}-\mathrm{H} 2,1.19 ; \mathrm{O} 1-\mathrm{H} 2,1.31$; C2-O1, 1.31; C2-O2, 1.45. In fact, a comparison of the solvent-corrected ground state energies of the esters $\mathbf{b}, \mathbf{c}$ and $\mathbf{h}$ reveals that esters with the conformation anti-coplanar to the carbonyl functionality are always higher in energies ( $\Delta \mathrm{G}_{\mathrm{THF}}, \Delta \mathrm{H}_{\mathrm{THF}}$ and $\left.\Delta \mathrm{E}_{\mathrm{THF}}\right)$ than their syn- 
conformers. The free energies are 10.8 and $6.5 \mathrm{kcal} / \mathrm{mol}$ higher for anti-methyl pivalate (b) and anti-tert-butyl acetate (c), respectively, compared to their syn-conformers. Although steric repulsion of the alkoxy group of the ester with the $\eta^{5}$-Cp* ligand is one of the factor that contributes to the increase in barrier height, it is apparent that the barrier height at such a transition state is dependent on the ground state energies of the ester substrate. As the alkoxy group can undergo conformational change at its ground state as a result of free rotation of the $\mathrm{C}-\mathrm{O}$ bond in solution, it is expected that catalysis should proceed with the lowest energy pathway, therefore, starting from the ester in a syn-coplanar conformation.

Ruthenium-assisted cleavage of the $\mathbf{C}-\mathbf{O}$ Bond of a hemiacetal coupled with proton transfer (Step C). The hydrogen-bonded 1-methoxyethanol molecule in structure $\mathbf{E}$ (Scheme 5) undergoes a rearrangement reaction in which the methoxy oxygen is in close proximity to ruthenium. This leads to a transition state structure $\mathbf{T S} \mathbf{S}_{\mathbf{E}, \mathbf{F}}$, which is $4.8 \mathrm{kcal} / \mathrm{mol}$ uphill $\left(\Delta \mathrm{G}_{\mathrm{THF}}^{\ddagger}\right)$ compared to $\mathbf{E}$ $\left(\Delta \mathrm{H}_{\mathrm{THF}}^{\ddagger}=3.0 \mathrm{kcal} / \mathrm{mol}\right)$. This structure shows a ruthenium-assisted cleavage of the $\mathrm{C}-\mathrm{O}$ bond in 1-methoxylethanol (Step $\mathrm{C}$ in Scheme 2), coupled with a proton transfer from the hydroxyl oxygen to the amido nitrogen, in a 6-membered ring transition state ( $v$ $=869 i \mathrm{~cm}^{-1}, \mathrm{C} 2-\mathrm{O} 2=1.52 ; \mathrm{N}-\mathrm{H}=1.20 \AA$, Figure 2, bottom). This forms a ruthenium-methoxide complex $(\mathbf{F})$ with a hydrogenbonded acetaldehyde through the $\mathrm{N}-\mathrm{H}$ group, which is $5.8 \mathrm{kcal} / \mathrm{mol}$ downhill $\left(\Delta \mathrm{G}_{\mathrm{THF}}\right)$. The loss of acetaldehyde and methanol regenerates the amido complex A (Scheme 5). ${ }^{48} \mathrm{Wang}$ and co-workers have modeled a similar transition state structure involving a proton transfer step during the $\mathrm{C}-\mathrm{O}$ bond cleavage of a hemiacetal catalyzed by complex $1 \mathbf{1 a} .^{28} \mathrm{An}$ IRC calculation on $\mathbf{T S}_{\mathrm{E}, \mathbf{F}}$ reveals that this is a concerted, synchronous reaction involving $\mathrm{C}-\mathrm{O}$ bond cleavage of the hemiacetal and a proton transfer from the $\mathrm{O}-\mathrm{H}$ bond to the amido nitrogen (see Figures S7 and S8 in SI).

Of interest, $\mathrm{Li}^{27}$ and Wang ${ }^{28}$ have calculated a transition state structure for the $\mathrm{C}-\mathrm{O}$ bond cleavage and a proton transfer step of 2methoxy-1-(methoxymethoxy)ethanol (hemiacetal of methoxymethyl 2-methoxyacetate) catalyzed by the same hemiacetal molecule in a 6-membered ring transition state. These have higher energies in comparison to our calculations for a rutheniumassisted $\mathrm{C}-\mathrm{O}$ bond cleavage $\left(\Delta \mathrm{G}^{\ddagger}\right.$ (TPSSTPSS $)=29.4 \mathrm{kcal} / \mathrm{mol} ; \Delta \mathrm{H}^{\ddagger}($ TPSSTPSS $)=17.7 \mathrm{kcal} / \mathrm{mol} ;{ }^{28} \Delta \mathrm{G}^{\ddagger}(\mathrm{B} 3 \mathrm{LYP})=27.9$ $\mathrm{kcal} / \mathrm{mol}^{27}$ ). It is likely that a transition-metal catalyzed reaction takes place during the course of the reaction as this provides a more feasible energy pathway.

\section{Scheme 5. Ruthenium-assisted Cleavage of the $\mathrm{C}-\mathrm{O}$ Bond Coupled with a Proton Transfer Step in 1-Methoxyethanol Starting from the Complex $\mathrm{E}^{a}$}

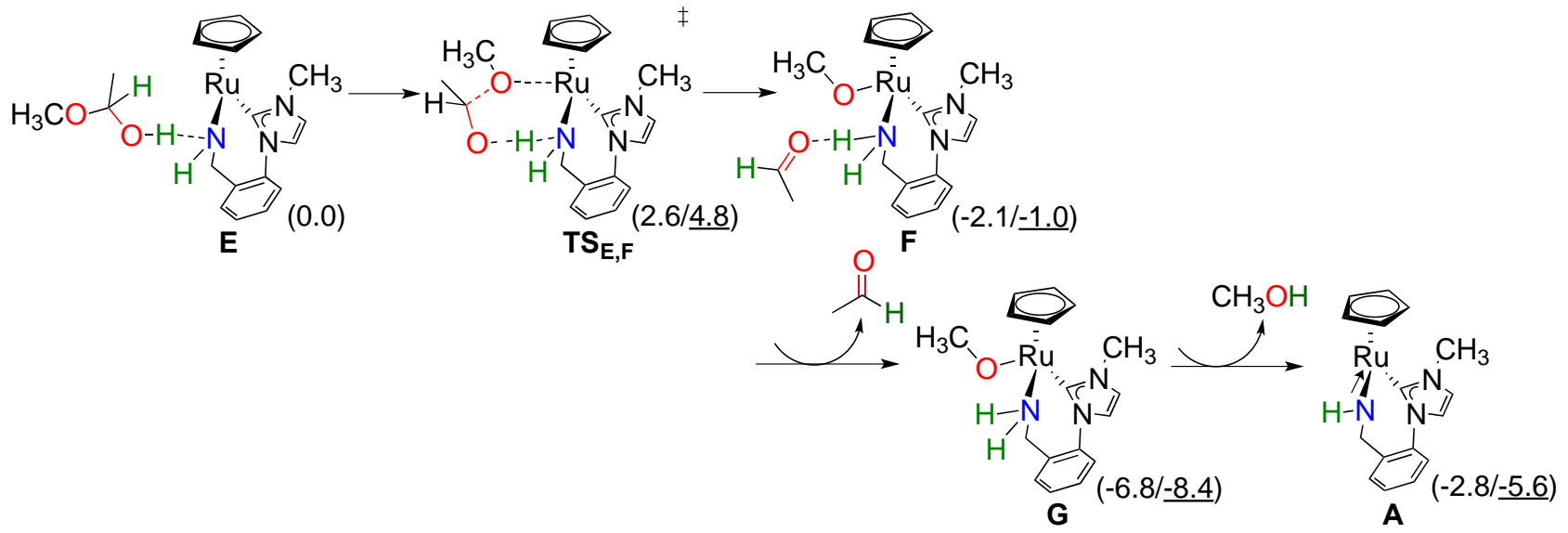

${ }^{\text {aStep } C}$ in Scheme 2. The gas phase and solvent-corrected free energies (M06/1 atm, and THF, $298 \mathrm{~K}$ ) are given in parentheses (in $\mathrm{kcal} / \mathrm{mol}$ ) relative to $\mathbf{E}$.

\section{Conclusions}

In conclusion, we report the catalytic activity and substrate scope for the hydrogenation of esters catalyzed by complex 2 containing an NHC-amine $\left(\mathrm{C}-\mathrm{NH}_{2}\right)$ ligand. This uses a moderate hydrogen pressure $(25 \mathrm{bar})$ and the reactions are carried out at a lower temperature $\left(50^{\circ} \mathrm{C}\right)$ than those of other reports. Our studies show that a concerted, asynchronous bifunctional mechanism for ester hydrogenation, via a six-membered ring transition state involving hydrogen-bonding interaction of the carbonyl oxygen of the ester and the $\mathrm{N}-\mathrm{H}$ group, is operative. The calculated energetics of the catalytic cycle (steps A to C in Scheme 2) for the hydrogenation of methyl acetate to acetaldehyde and methanol are summarized in Figure 6: the largest energy barrier in this cycle appears to be the transfer of a $\mathrm{Ru}-\mathrm{H} / \mathrm{N}-\mathrm{H}$ pair from $\mathbf{C}$ to the carbonyl group of methyl acetate in a 6-membered ring transition state (TS $\left.\mathbf{S}_{\mathbf{D}, \mathbf{E}}\right)$. This has a solvent-corrected free energy barrier $\left(\Delta \mathrm{G}^{\dagger} \mathrm{THF}\right)$ of $22.3 \mathrm{kcal} / \mathrm{mol}$ for a $R e$-face attack by the $\mathrm{Ru}-\mathrm{H}$ bond, or 22.2 $\mathrm{kcal} / \mathrm{mol}$ for a $\mathrm{Si}$-face attack. This is an enthalpy driven process. The ruthenium-assisted cleavage of the $\mathrm{C}-\mathrm{O}$ bond coupled with a 
proton transfer step starting from $\mathbf{E}$ is associated with a small free energy barrier $\left(\Delta \mathrm{G}^{\ddagger} \mathrm{THF}=4.8 \mathrm{kcal} / \mathrm{mol}\right)$. This is, on the other hand, an entropy driven process.

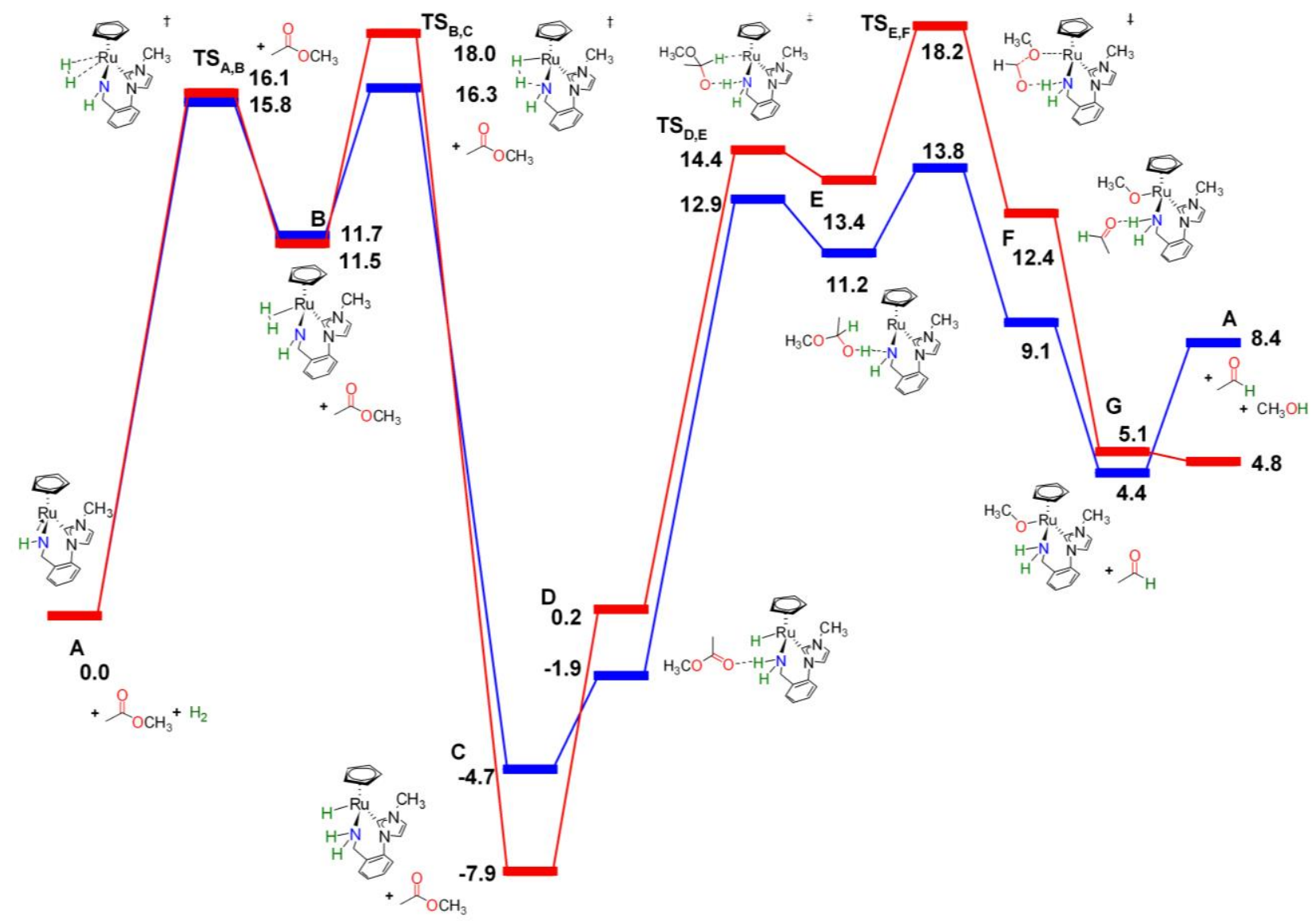

Figure 6. The energy profile for outer-sphere bifunctional mechanism in the hydrogenation of methyl acetate to acetaldehyde and methanol (Steps A, B and C in Scheme 2) starting from the amido complex $\mathbf{A}, \mathrm{H}_{2}$, and methyl acetate and moving to the right. The blue pathway shows the gas phase free energies $(\Delta \mathrm{G}, 1 \mathrm{~atm}, 298 \mathrm{~K})$ and the red pathway shows the solvent-corrected free energies (THF, $298 \mathrm{~K}$ ). All of the free energies are reported relative to $\mathbf{A}, \mathrm{H}_{2}$, and methyl acetate, in $\mathrm{kcal} / \mathrm{mol}$.

According to our calculations, the difference in rates of hydrogenation with esters of different steric bulk is attributed to the difference in ground state energies of the esters, which in turn contributes to the barrier height of such bifunctional transition states. We suggest that the ground state energies of the different conformers of the ester (syn-or anti-coplanar) contribute to the barrier height for ester hydrogenation. This study will contribute to the expanding research areas that include coupling reactions using hydrogen borrow methodology, ${ }^{49}$ and the hydrogenation of polar double bonds such as organic carbonates. ${ }^{29-31}$

\section{Experimental Section}

Computational details. All density functional theory (DFT) calculations were performed using the Gaussian $09^{50}$ package with the M06 $^{34,35}$ functional. This was shown to give better predictions of geometric parameters in organometallic compounds. ${ }^{35,36}$

Ruthenium was treated with the SDD ${ }^{51,52}$ relativistic effective core potential and an associated basic set. The keywords $6 \mathrm{~d}$ and $10 \mathrm{f}$ were used to specify the use of Cartesian $\mathrm{d}$ and f functions. The 10f polarization function was given the exponent of 1.24, obtained from a study by Frenking and co-workers. ${ }^{53}$ All other atoms were treated with the double- $\zeta$ basis set $6-31++\mathrm{G}^{* *}$ which includes diffuse functionals ${ }^{54,55}$ and additional $p$-orbitals on hydrogen as well as additional $d$-orbitals on carbon, nitrogen and oxygen. ${ }^{56}$ All geometry optimizations were conducted in the gas phase, and the stationary points were characterized by normal mode analysis. Reported free energies were obtained at $1 \mathrm{~atm}$ and $298 \mathrm{~K}$ using unscaled vibrational frequencies. All transition states reported were 
found to have a single imaginary frequency. Solvent correction (THF) was made thereafter to the gas-phase-optimized structures using the intergral equation formalism polarization continuum model (IEF-PCM) ${ }^{37,38}$ with radii and nonelectrostatic terms from Truhlar's SMD solvation model. ${ }^{39}$

Acknowledgement. The NSERC Canada is thanked for a Discovery Grant to R. H. Morris and a graduate scholarship to W. W. N. O. Professor F. Hasanayn is thanked for the fruitful discussion with computational studies.

Supporting Information (SI) Available: Details for catalysis, Cartesian coordinates, energies for all of the computed structures and the complete citation for reference 50 (PDF), and AVI files giving animations for loose vibrations characterizing the computed transition states. These material are available free of charge via the Internet at http://pubs.acs.org.

\section{References}

1. Ito, M.; Ikariya, T., Chem. Commun. 2007, 5134-5142.

2. Kubas, G. J., Chem. Rev. 2007, 107, 4152-4205.

3. $\quad$ Grey, R. A.; Pez, G. P.; Wallo, A., J. Am Chem Soc. 1981, 103, 7536-7542.

4. van Engelen, M. C.; Teunissen, H. T.; de Vries, J. G.; Elsevier, C. J., J. Mol. Catal. A-Chem. 2003, 206, 185-192.

5. Zhang, J.; Leitus, G.; Ben-David, Y.; Milstein, D., Angew. Chem.-Int. Ed. 2006, 45, 1113-1115.

6. $\quad$ Saudan, L. A.; Saudan, C. M.; Debieux, C.; Wyss, P., Angew. Chem.-Int. Ed. 2007, 46, 7473-7476.

7. $\quad$ Clarke, M. L.; Diaz-Valenzuela, M. B.; Slawin, A. M. Z., Organometallics 2007, 26, 16-19.

8. Dub, P. A.; Ikariya, T., ACS Catal. 2012, 2, 1718-1741.

9. $\quad$ Wiberg, K. B.; Crocker, L. S.; Morgan, K. M., J. Am Chem Soc. 1991, 113, 3447-3450.

10. Bertoli, M.; Choualeb, A.; Gusev, D. G.; Lough, A. J.; Major, Q.; Moore, B., Dalton Trans. 2011, 40, 8941-8949.

11. O, W. W. N.; Lough, A. J.; Morris, R. H., Organometallics 2012, 31, 2137-2151.

12. Ikariya, T., Bull. Chem. Soc. Jpn. 2011, 84, 1-16.

13. Askevold, B.; Roesky, H. W.; Schneider, S., ChemCatChem 2012, 4, 307-320.

14. Fogler, E.; Balaraman, E.; Ben-David, Y.; Leitus, G.; Shimon, L. J. W.; Milstein, D., Organometallics 2011, 30, 3826-

3833.

15. Sun, Y.; Koehler, C.; Tan, R.; Annibale, V. T.; Song, D., Chem. Commun. 2011, 47, 8349-8351.

16. Diez-Gonzalez, S.; Marion, N.; Nolan, S. P., Chem. Rev. 2009, 109, 3612-3676.

17. Kuriyama, W.; Ino, Y.; Ogata, O.; Sayo, N.; Saito, T., Adv. Synth. Catal. 2010, 352, 92-96.

18. Kuriyama, W.; Matsumoto, T.; Ogata, O.; Ino, Y.; Aoki, K.; Tanaka, S.; Ishida, K.; Kobayashi, T.; Sayo, N.; Saito, T., Org. Process Res. Dev. 2012, 16, 166-171.

19. Spasyuk, D.; Smith, S.; Gusev, D. G., Angew. Chem. Int. Ed. 2012, 51, 2772-2775.

20. Acosta-Ramirez, A.; Bertoli, M.; Gusev, D. G.; Schlaf, M., Green Chem. 2012, 14, 1178-1188.

21. Carpenter, I.; Eckelmann, S. C.; Kuntz, M. T.; Fuentes, J. A.; France, M. B.; Clarke, M. L., Dalton Trans. 2012, 41, 10136-10140.

22. Touge, T.; Hakamata, T.; Nara, H.; Kobayashi, T.; Sayo, N.; Saito, T.; Kayaki, Y.; Ikariya, T., J. Am Chem Soc. 2011, $133,14960-14963$.

23. Ito, M.; Ootsuka, T.; Watari, R.; Shiibashi, A.; Himizu, A.; Ikariya, T., J. Am Chem Soc. 2011, 133, 4240-4242.

24. Noyori, R.; Yamakawa, M.; Hashiguchi, S., J. Org. Chem. 2001, 66, 7931-7944.

25. Clapham, S. E.; Hadzovic, A.; Morris, R. H., Coord. Chem. Rev. 2004, 248, 2201-2237.

26. Takebayashi, S.; Bergens, S. H., Organometallics 2009, 28, 2349-2351.

27. Zeng, G. X.; Li, S. H., Inorg. Chem. 2011, 50, 10572-10580.

28. Li, H. X.; Wang, X. T.; Huang, F.; Lu, G.; Jiang, J. L.; Wang, Z. X., Organometallics 2011, 30, 5233-5247.

29. Yang, X. Z., ACS Catal. 2012, 2, 964-970.

30. Li, H. X.; Wen, M. W.; Wang, Z. X., Inorg. Chem. 2012, 51, 5716-5727.

31. Balaraman, E.; Gunanathan, C.; Zhang, J.; Shimon, L. J. W.; Milstein, D., Nat. Chem. 2011, 3, 609-614.

32. O, W. W. N.; Lough, A. J.; Morris, R. H., Chem. Commun. 2010, 46, 8240 - 8242.

33. O, W. W. N.; Lough, A. J.; Morris, R. H., Organometallics 2012, 31, 2152-2165.

34. Zhao, Y.; Truhlar, D. G., J. Chem. Phys. 2006, 125, 194101-1-194101-18

35. Zhao, Y.; Truhlar, D. G., Theor. Chem. Acc. 2008, 120, 215-241.

36. Kulkarni, A. D.; Truhlar, D. G., J. Chem. Theory Comput. 2011, 7, 2325-2332.

37. Tomasi, J.; Mennucci, B.; Cances, E., J. Mol. Struct. (THEOCHEM) 1999, 464, 211-226.

38. Tomasi, J.; Mennucci, B.; Cammi, R., Chem. Rev. 2005, 105, 2999-3093.

39. Marenich, A. V.; Cramer, C. J.; Truhlar, D. G., J. Phys. Chem. B 2009, 113, 6378-6396.

40. Handgraaf, J. W.; Meijer, E. J., J. Am. Chem. Soc. 2007, 129, 3099-3103.

41. Chen, Y.; Liu, S. B.; Lei, M., J. Phys. Chem. C 2008, 112, 13524-13527. 
42. Bertoli, M.; Choualeb, A.; Lough, A. J.; Moore, B.; Spasyuk, D.; Gusev, D. G., Organometallics 2011, 30 , $3479-3482$

43. Bosch, E.; Moreno, M.; Lluch, J. M.; Bertran, J., Chem. Phys. Lett. 1989, 160, 543-548.

44. Koseki, S.; Gordon, M. S., J. Phys. Chem. 1989, 93, 118-125.

45. Espinosagarcia, J.; Corchado, J. C., J. Phys. Chem. 1995, 99, 8613-8616.

46. Yamakawa, M.; Ito, H.; Noyori, R., J. Am. Chem. Soc. 2000, 122, 1466-1478.

47. Chan, B.; Radom, L., J. Am. Chem. Soc. 2005, 127, 2443-2454.

48. Hasanayn, F.; Morris, R. H., Inorg. Chem. 2012, 51, 10808-10818.

49. Nielsen, M.; Junge, H.; Kammer, A.; Beller, M., Angew. Chem.-Int. Edit. 2012, 51, 5711-5713.

50. $\quad$ Frisch, M. J., et al., Gaussian 09, Revision A.1; Gaussian Inc.: Wallingford, CT 2009.

51. Andrae, D.; Haussermann, U.; Dolg, M.; Stoll, H.; Preuss, H., Theor. Chim. Acta 1990, 77, $123-141$.

52. Leininger, T.; Nicklass, A.; Stoll, H.; Dolg, M.; Schwerdtfeger, P., J. Chem. Phys. 1996, 105, $1052-1059$.

53. Ehlers, A. W.; Bohme, M.; Dapprich, S.; Gobbi, A.; Hollwarth, A.; Jonas, V.; Kohler, K. F.; Stegmann, R.; Veldkamp, A.; Frenking, G., Chem. Phys. Lett. 1993, 208, 111-114.

54. Clark, T.; Chandrasekhar, J.; Spitznagel, G. W.; Schleyer, P. V., J. Comput. Chem. 1983, 4, $294-301$.

55. Lynch, B. J.; Zhao, Y.; Truhlar, D. G., J. Phys. Chem. A 2003, 107, 1384-1388.

56. Frisch, M. J.; Pople, J. A.; Binkley, J. S., J. Chem. Phys. 1984, 80, 3265-3269. 